\title{
BEMERKUNGEN \\ ZUR VORLIEGENDEN AUFLAGE
}

Den Schnitt zwischen der Einleitung über die griechische Tragödie und den beiden Bänden, die sich eigentlich auf Euripides' Herakles beziehen, hat Wilamowitz-Moellendorff durch verschiedene Abdrucke hin festgehalten. Die verselbständigte Einleitung (d. h. die Kapitel 1 bis 4) ist 1906 und 1910 in unverändertem Nachdruck als Einzelband neu aufgelegt worden.

Die vorliegende Ausgabe verbindet die Gesichtspunkte, die das Werk ursprünglich bestimmt haben, mit denen, die zu der Teilung führten:

Wie in der Erstausgabe soll die Einleitung in die griechische Tragödie wieder mit einbezogen werden, jedoch als selbständiger Band I. Daraus ergibt sich die Einteilung in drei Bände:

Band I enthält die ursprünglichen Kapitel I bis IV, denen das Vorwort der ursprünglichen zweibändigen Ausgabe vorangestellt ist,

Band II den ersten Band der zweibändigen Ausgabe nach Abtrennung des Vorwortes,

Band III den zweiten Band der zweibändigen Ausgabe.

Bei einem späteren Nachdruck lieB Wilamowitz-Moellendorff die deutsche Utbersetzung der Dichtung weg, da er sie anderwärts zugänglich wußte. Da dies heute nicht mehr der Fall ist, ist die Utbersetzung wie in der Ausgabe von 1895 wieder mit aufgenommen. 
